\title{
Design and Bandwidth Optimization on Triangle Patch Microstrip Antenna for WLAN 2.4 GHz
}

\author{
Sotyohadi, Riken Afandi, and Dony Rachmad Hadi \\ Department of Electrical Engineering, National Institute of Technology (ITN) Malang, \\ Jalan Raya Karanglo km 2, Malang 65145, East Java, Indonesia
}

\begin{abstract}
In this paper, single and dual element triangle patch microstrip antenna for WLAN $2.4 \mathrm{GHz}$ is designed, analyzed and fabricated. Both proposed design utilized proximity feeding techniques. Afterwards the design is simulated on HFFS and optimized, which finally the dimension of both design for frequency $2.4 \mathrm{GHz}$ is obtained. The best simulation result for both single and dual element triangle patch microstrip antenna is used as reference for fabrication on FR4 substrate with dielectric constant $(\square \mathrm{r})=4.4$ and thickness $(\mathrm{h})=1.6 \mathrm{~mm}$. The measurement result showed that the single element can achieve return loss (S11) -51.913 dB and VSWR 1.0059 at $2.417 \mathrm{GHz}$, and then for dual element the result for return loss (S1) is -48.2138 for VSWR 1.0078 at $2.463 \mathrm{GHz}$. Compared to coaxial feeding technique, the proximity feeding has better parameter performance.
\end{abstract}

Key words: Coaxial feeding, HFFS, microstrip antenna, proximity feeding, return loss

\section{Introduction}

Microstrip antenna becomes more popular recently because of its advantages compared to the conventional antennas, such as Yagi-Uda, horn, helical, and parabolic. Even though they have higher gain and wider bandwidth, but the typical dimensional structure and large size are not applicable for compact wireless devices [1]. In the other hand, the microstrip antenna has several major superiorities such as light weight, low profile, small in size, ease to integrate with Microwave Integrated Circuit (MIC) and Monolithic Microwave Integrated Circuit (MMIC) [2]. Instead of its superiority, the poor bandwidth, low efficiency and gain become the weaknesses of microstrip antenna [3]. There are numerous methods that can be utilized to overcome this problem. One method that can be used to improve the microstrip antenna parameters is the feeding technique. Previous research has been conducted to analyze the effect of using different feeding technique on microstrip antenna, in which the result showed that the cut feed has better parameter performance compared to coaxial and microstrip line feeding technique [4]. From the previous research for cut feed or microstrip line feed with notch, the bandwidth only up to $60 \mathrm{MHz}$ [5]. Furthermore, since bandwidth is one of the essential parameters for WLAN $2.4 \mathrm{GHz}$ which should cover in the range of $100 \mathrm{MHz}$ [6], better feeding technique should be utilized. In

* Corresponding author: sotyohadi@lecturer.itn.ac.id 
order to accommodate wider bandwidth, the proximity coupled feeding is one of feeding techniques which has better characteristics in suppressing the spurious feed radiation and enhance bandwidth [7]. Therefore, the use of proximity coupled feeding in present research design on microstrip antenna is considerable.

The aim of this research is to design and analyze a single and dual element triangle patch microstrip antenna utilized proximity coupled feeding. The decision on using triangle patch microstrip antenna is based on the reason that the area of triangle patch has fewer dimensions for the specified operation frequency [8]. Afterwards, the fabricated design is measured and compared to the bandwidth result of triangle patch microstrip antenna which utilized the coaxial feeding technique.

\section{Antenna design}

The triangle patch microstrip antenna is design to operate for $2.4 \mathrm{GHz}$. The design is fabricated on the dielectric substrate FR4, which has the dielectric permittivity constant of the substrate $(\varepsilon r)=4.4$ and thickness of the substrate $(\mathrm{h})=1.6 \mathrm{~mm}$.

\subsection{Resonant frequency}

Resonant frequency determines the dimension of the microstrip antenna. Therefore the corresponding resonance frequency is determine by reference [9]

$$
f_{r}=\frac{c k_{m n}}{2 \pi \sqrt{\varepsilon_{r}}}=\frac{2 c}{3 a \sqrt{\varepsilon_{r}}}\left(m^{2}+m n+n^{2}\right)
$$

Where $c$ is velocity of light in free space and $K_{m n}$ is wave number. The wave number can be determined by reference [9]

$$
K_{m n}=\frac{4 \pi}{3 a} \sqrt{m^{2}+m n+n^{2}}
$$

Therefore, from the above equation for lowest order resonance frequency, is given [9]

$$
f_{r}=\frac{2 c}{3 a \sqrt{\varepsilon_{r}}}
$$

Where:

$f_{r}=$ resonance frequency

$a=$ length of the side triangular patch

$\varepsilon_{r}=$ relative dielectric constant of substrate

\subsection{Triangular patch dimension}

The triangular patch has three sides with $a$ length, as shown in Figure 1 [10]. 


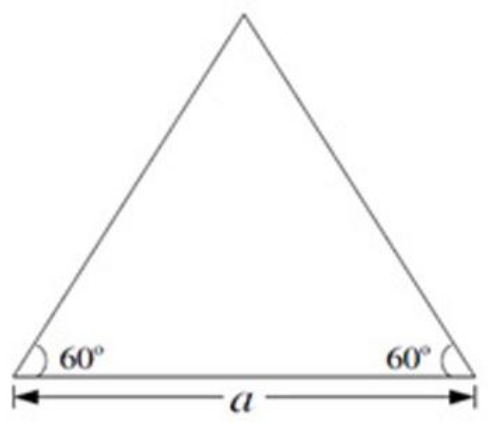

Fig. 1. Triangular patch microstrip antenna.

After substituting the above equation with the given value for $f_{r}=2.44 \mathrm{GHz}$ as the centre frequency for WLAN, velocity of light $c=3 \times 10^{8} \mathrm{~m} \mathrm{~s}^{-1}$, and $\varepsilon_{r}=4.4$, the length of $a$ can be calculated. In order to determine length of triangle patch $a$, the Eq. 2 is utilized which give the result [11].

$$
a=\frac{2 c}{3 f_{r} \sqrt{\varepsilon_{r}}}
$$

Finally, the value for length of triangle is obtained $a=39.0763 \mathrm{~mm}$. Thus the height $\left(L_{P}\right)$ is determined by mathematical equation as follow,

$$
H=L_{p}=\sqrt{a^{2}-\left(\frac{1}{2} \times a\right)^{2}}
$$

From above Eq.4 for $a=39.0763 \mathrm{~mm}$, it can be calculated that the height of triangle patch $L_{P}=33.7749 \mathrm{~mm}$.

\subsection{Ground plane dimension}

The ground plane is an area which located in the bottom side. The position of ground plane is shown in Figure 2.

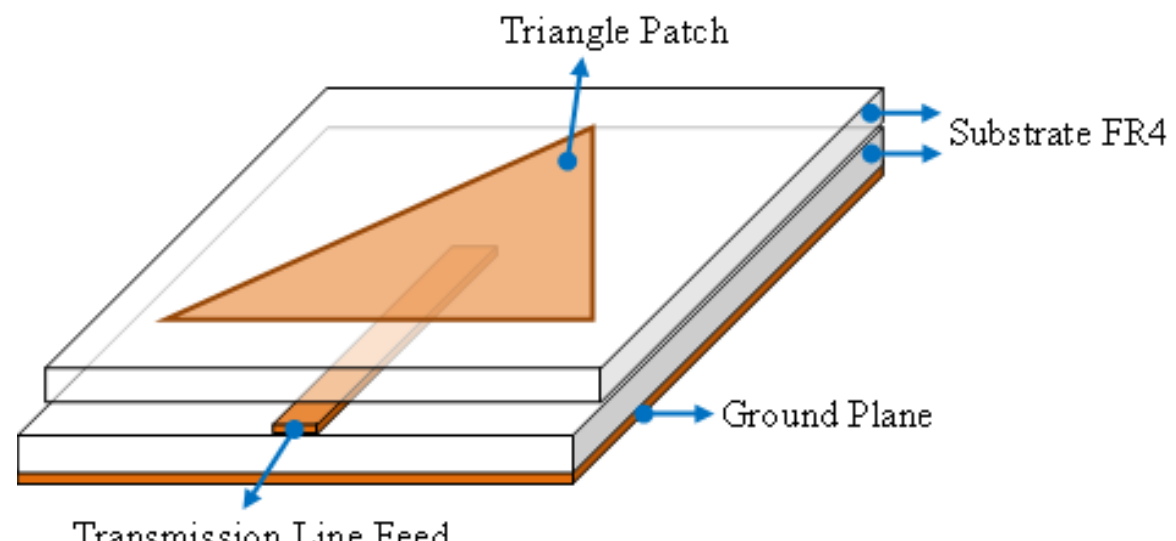

Fig. 2. Ground plane triangular patch microstrip antenna. 
According to Punit S. Nakar the size of ground plane is larger than the patch dimensions by approximately six times the height or thickness of the substrate all around the periphery. Hence for the dimension design of the ground plane is determined by reference [12],

$$
\begin{gathered}
L_{g}=6 h+L_{p} \\
L_{g}=6 \times 1.6+33.7749=43.3749 \mathrm{~mm} \\
W_{g}=6 h+W_{p} \\
W_{g}=6 \times 1.6+39.0763=48.6763 \mathrm{~mm}
\end{gathered}
$$

\subsection{Proximity coupled feeding}

In proximity coupled feeding eventually is arrange in stack of substrate layer, which mainly the feeding technique is similar to that microstrip line feeding. The dimension of the microstrip line feeding has important value in order to have matching condition between impedance of the triangle patch microstrip antenna and the transmission line. Therefore the width and length of $Z_{0}=50 \Omega$ microstrip feed line for single element can be determined from the following Equation [3],

$$
W_{f}=\frac{2 h}{\pi}\left(B-1-\ln (2 B-1)+\frac{\varepsilon_{r}-1}{2 \varepsilon_{r}}\left[\ln (B-1)+0.39-\frac{0.61}{\varepsilon_{r}}\right]\right)
$$

Where $h=1.6, B=5.64$ and $\varepsilon_{r}=4.4$ then the result for feed line width can be obtained $W_{f}$ $=3 \mathrm{~mm}$. The following step is calculating of the $50 \Omega$ microstrip feed line which can be obtain from the following Equation [3],

$$
L_{f 1}=\frac{\lambda_{g}}{4}=\frac{56.23}{4}=14.0575 \mathrm{~mm}
$$

From Equation 8, where the value for $\lambda_{g}=56.23 \mathrm{~mm}$, then the result for $L_{f l}=14.0575$ $\mathrm{mm}$.

For dual element triangle patch, the T-Junction $70.7 \Omega$ is needed to divide the power for both patches [13]. Figure 3 shows for the power divider to connect the both triangle patch microstrip antenna.

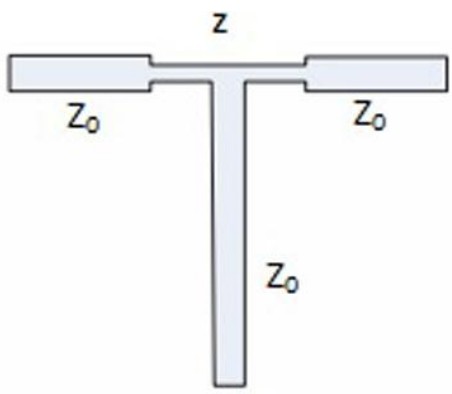

Fig. 3. T-Junction as power divider

In order to maintain the input impedance $50 \Omega, 1 / 4 \lambda$ transformer is needed. The $1 / 4 \lambda$ transformer is an impedance matching technique by providing transmission line impedance $Z_{t}$ between two non-match transmission channels. To acquire the width of the $Z_{0}=70.7 \Omega$ can be determined using Equation 7. 
For $B=3.96, \varepsilon_{r}=4.4$, and the thickness for substrate $h=1.6 \mathrm{~mm}$, the width of the feed line is obtained $W_{f}=1.58 \mathrm{~mm}$. Thus, the length can be obtained by using Equation 8 , for $\lambda_{g}$ $=43.29 \mathrm{~mm}$.

$$
L_{f 2}=\frac{\lambda_{g}}{4}=\frac{43.29}{4}=10.8225 \mathrm{~mm}
$$

\subsection{Distance between two elements}

For dual element the distance between both patches should be calculated, this is due to the electromagnetically coupled effect. Therefore, the distance between two elements can be calculated using Equation 9.

$$
\begin{aligned}
d & =\frac{c}{2 f} \\
d & =\frac{3 \times 10^{8}}{2 \times 2.44 \times 10^{9}}=61.4754 \mathrm{~mm}
\end{aligned}
$$

Finally the distance between two triangle patch microstrip antenna is defined $d=61.4754$ $\mathrm{mm}$.

\section{Proposed antenna}

\subsection{Single element triangle patch}

The single element triangle patch microstrip antenna with proximity feeding technique are shown in Figure 4.

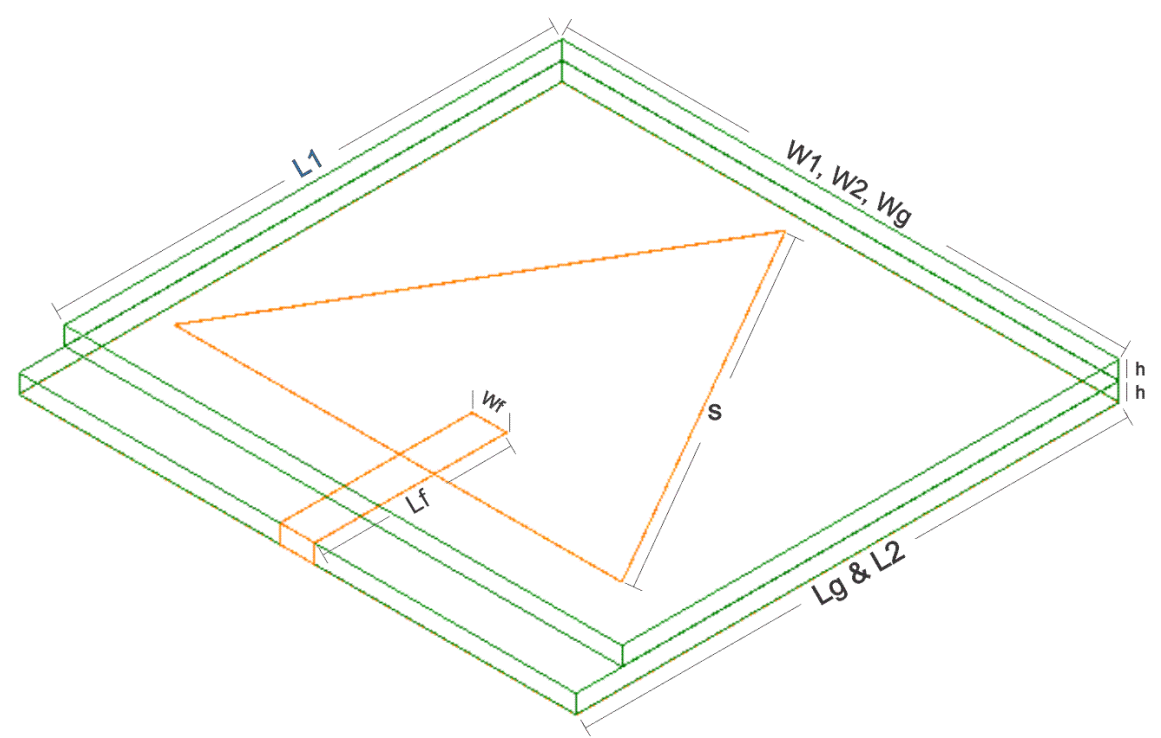

Fig. 4. Single element triangular patch microstrip antenna

From the Figure 4 above, the dimension of proposed antenna for single element is given in the Table 1. 
Table 1. Proposed single element triangle patch.

\begin{tabular}{|c|l|c|}
\hline No. & \multicolumn{1}{|c|}{ Antenna Dimension } & Value $(\mathrm{mm})$ \\
\hline 1 & $a$ (length of triangle patch) & 39.0763 \\
\hline 2 & $L_{l}$ (length of upper substrate) & 43.3749 \\
\hline 3 & $L_{2}$ (length of lower substrate) & 47.4410 \\
\hline 4 & $L_{g}$ (length of ground plane) & 47.4410 \\
\hline 5 & $W_{l}$ (width of upper substrate) & 48.6763 \\
\hline 6 & $W_{2}$ (width of lower substrate) & 48.6763 \\
\hline 7 & $W_{g}$ (width of ground plane) & 48.6763 \\
\hline 8 & $h$ (thickness of substrate) & 1.6 \\
\hline 9 & $\begin{array}{l}L_{f} \text { (length of microstrip } \\
\text { feedline) }\end{array}$ & 16.7608 \\
\hline 10 & $\begin{array}{l}W_{f} \text { (width of microstrip } \\
\text { feedline) }\end{array}$ & 3.0216 \\
\hline
\end{tabular}

\subsection{Dual element triangle patch}

The following Figure 4 is shown for dual element triangle patch microstrip antenna.

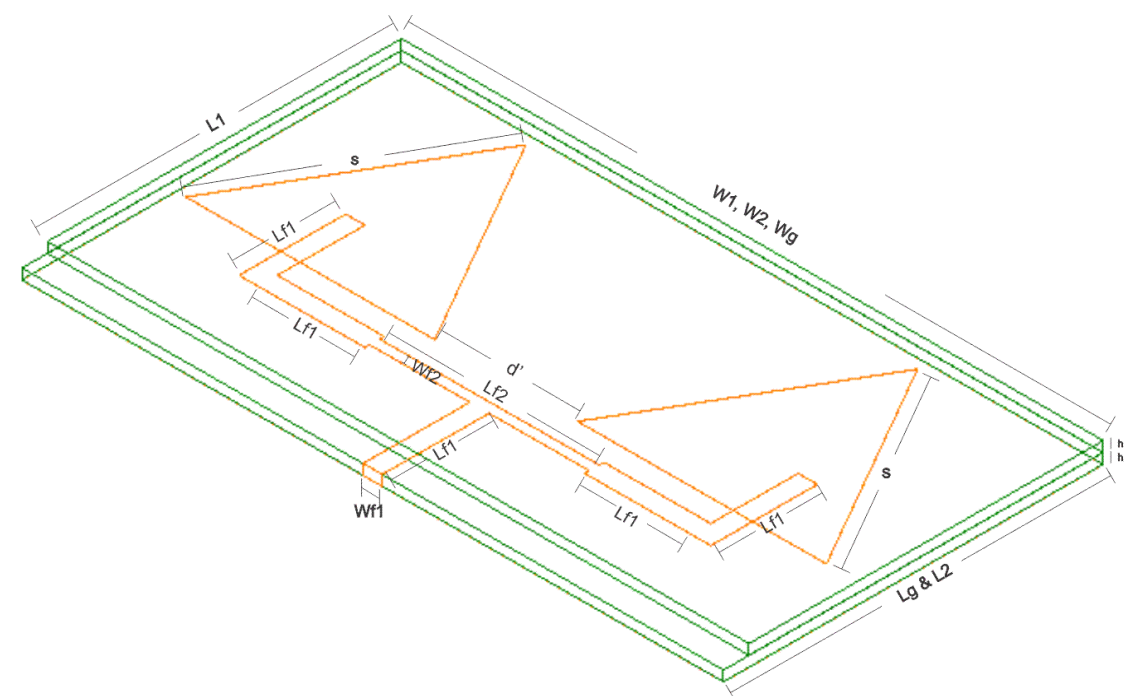

Fig. 5. Dual element triangular patch microstrip antenna.

The dimension of Figure 5 above and include the impedance matching is given in the following Table 2 .

Table 2. Proposed dual element triangle patch.

\begin{tabular}{|c|l|c|}
\hline No. & \multicolumn{1}{|c|}{ Antenna Dimension } & Value $(\mathrm{mm})$ \\
\hline 1 & $a$ (length of triangle patch) & 39.0763 \\
\hline 2 & $L_{1}$ (length of upper substrate) & 55.6014 \\
\hline 3 & $L_{2}$ (length of lower substrate) & 59.6014 \\
\hline 4 & $L_{g}$ (length of ground plane) & 59.6014 \\
\hline 5 & $W_{l}$ (width of upper substrate) & 110.1517 \\
\hline 6 & $W_{2}$ (width of lower substrate) & 110.1517 \\
\hline
\end{tabular}

Continue on next page 
Table 2. Proposed dual element triangle patch (Continue).

\begin{tabular}{|c|l|c|}
\hline No. & \multicolumn{1}{|c|}{ Antenna Dimension } & Value $(\mathrm{mm})$ \\
\hline 7 & $W_{g}$ (width of ground plane) & 110.1517 \\
\hline 8 & $h$ (thickness of substrate) & 1.6 \\
\hline 9 & $L_{f 1}$ (length of microstrip feedline $50 \Omega$ ) & 16.7608 \\
\hline 10 & $W_{f 1}$ (width of microstrip feedline $\left.50 \Omega\right)$ & 3.0216 \\
\hline 11 & $\begin{array}{l}L_{f 2} \text { (length of microstrip feedline } 70,7 \\
\Omega)\end{array}$ & 34.507 \\
\hline 12 & $\begin{array}{l}W_{f 2} \text { (width of microstrip feedline 70,7 } \\
\Omega)\end{array}$ & 1.57342 \\
\hline 13 & $d$ (distance of both patches) & 22.3991 \\
\hline
\end{tabular}

\section{Simulation result}

\subsection{Return loss}

For good result, the return loss (S11) should be less than $-10 \mathrm{~dB}$. In which the $-10 \mathrm{~dB}$ is equivalent to VSWR $>2$. From Figure 6 it is clear that the simulation result after optimization for single element for $\mathrm{S} 11$ is $-31.9556 \mathrm{~dB}$ at resonance frequency $2.42 \mathrm{GHz}$.

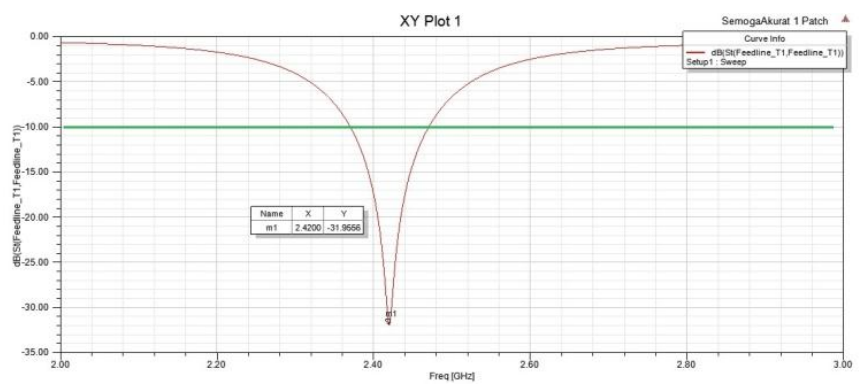

Fig. 6. Return loss (S11) for single element

The following Figure 7 it is depicted the return loss for dual element. After optimization the value of S11 is $-24.3672 \mathrm{~dB}$ at resonance frequency $2.434 \mathrm{GHz}$.

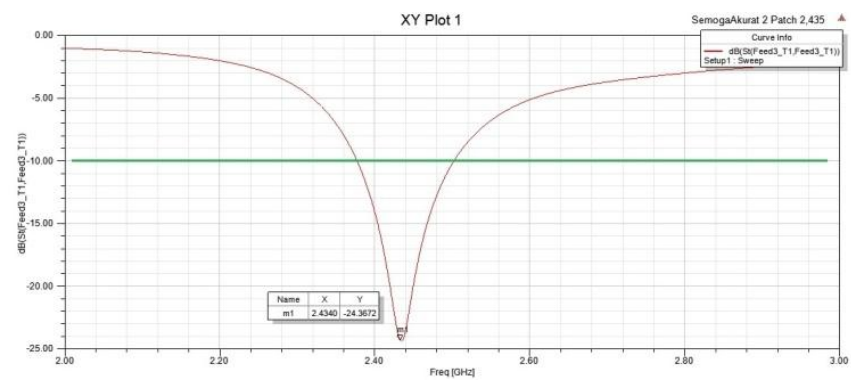

Fig. 7. Return loss (S11) for dual element. 


\subsection{VSWR}

Voltage Standing Wave Ratio (VSWR) is the reflection coefficient. The VSWR for single element is presented in Figure 8, which shows the optimized simulated result for VSWR $=1.0518$, which is less than 2 .

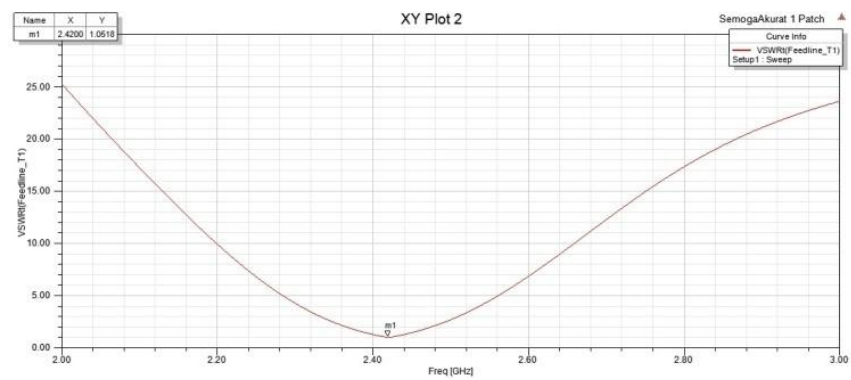

Fig. 8. Simulated VSWR for single element.

In Figure 9, shows the optimized simulation result for dual element VSWR $=1.1288$

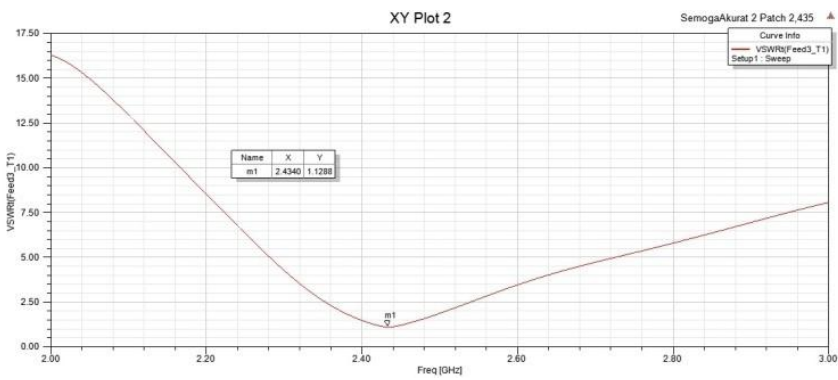

Fig. 9. Simulated VSWR for dual element.

\section{Measurement result}

\subsection{Return loss}

The measurement result for return loss (S11) is shown in Figure 10 for single element and Figure 11 for dual element. Both measurements were performed using vector network analyzer (VNA). 


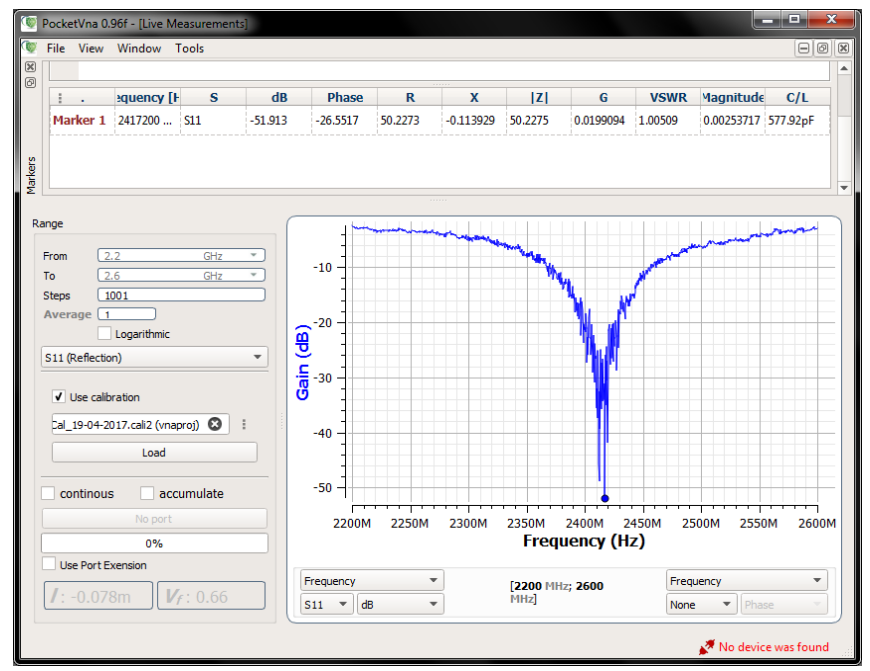

Fig. 10. Return loss for single patch element.

The obtained return loss for measurement in single patch is $-51.913 \mathrm{~dB}$ at resonant frequency of $2.417 \mathrm{GHz}$.

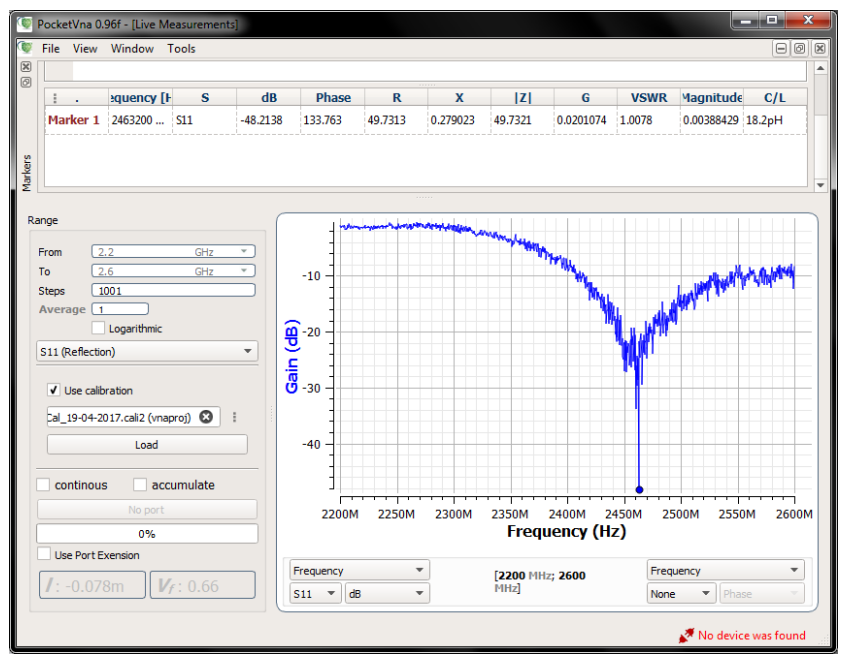

Fig. 11. Return loss for dual patch element.

The measurement result for dual element is $-48.2138 \mathrm{~dB}$ at the resonant frequency of $2.463 \mathrm{GHz}$.

\subsection{VSWR}

For VSWR measurement result is shown in Figure 12 for single element and in Figure 13 for the dual element. The obtained measurement result for single and dual element is 1.0059 and 1.0078 respectively. 


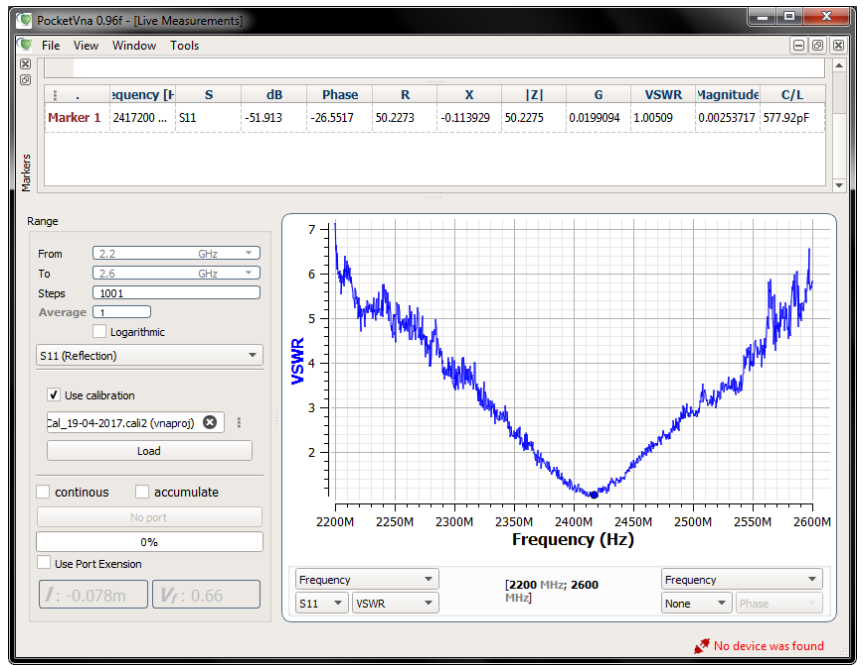

Fig. 12. VSWR for single patch element.

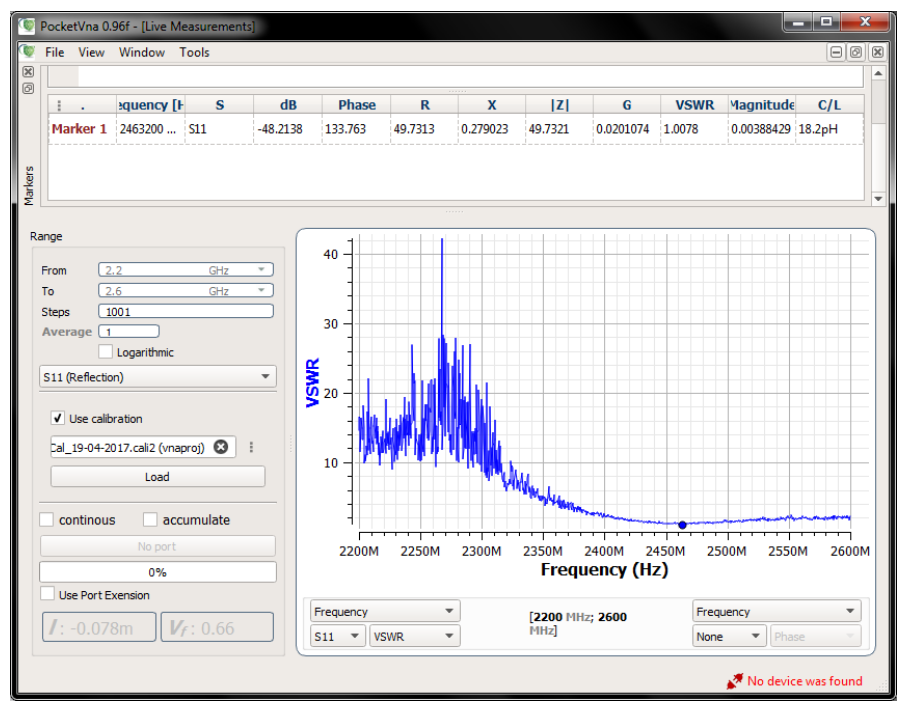

Fig. 13. VSWR for dual patch element.

\subsection{Bandwidth}

Bandwidth of antenna is capability of an antenna to cope range of frequency within the antenna operation frequency, which is less than $-10 \mathrm{~dB}$ return loss value. The following Figure 14 and Figure 15 show the bandwidth result for single and dual triangle patch antenna. 


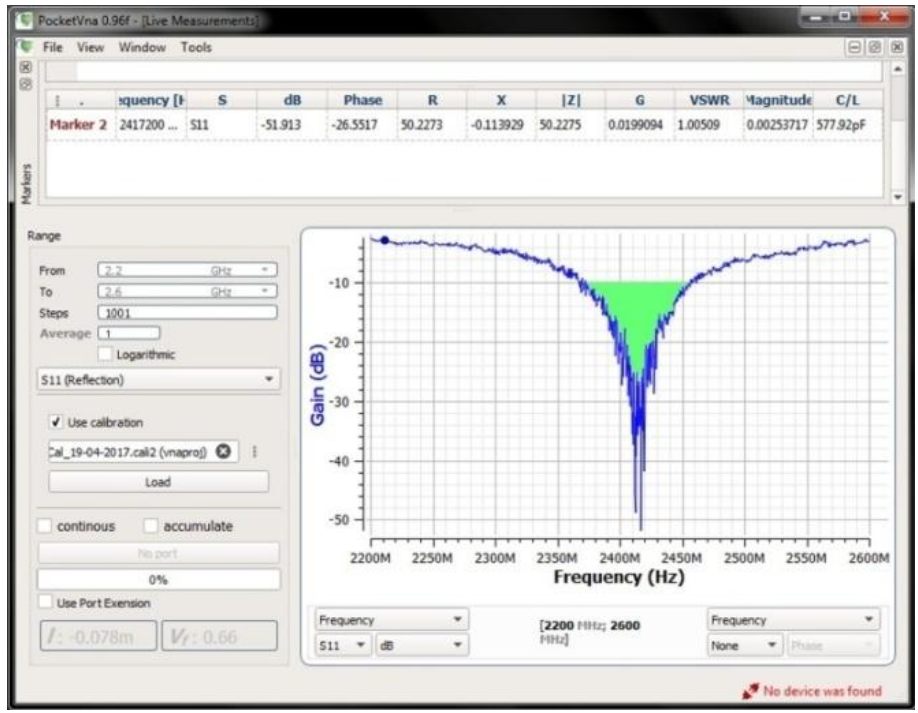

Fig. 14. Bandwidth for single patch element.

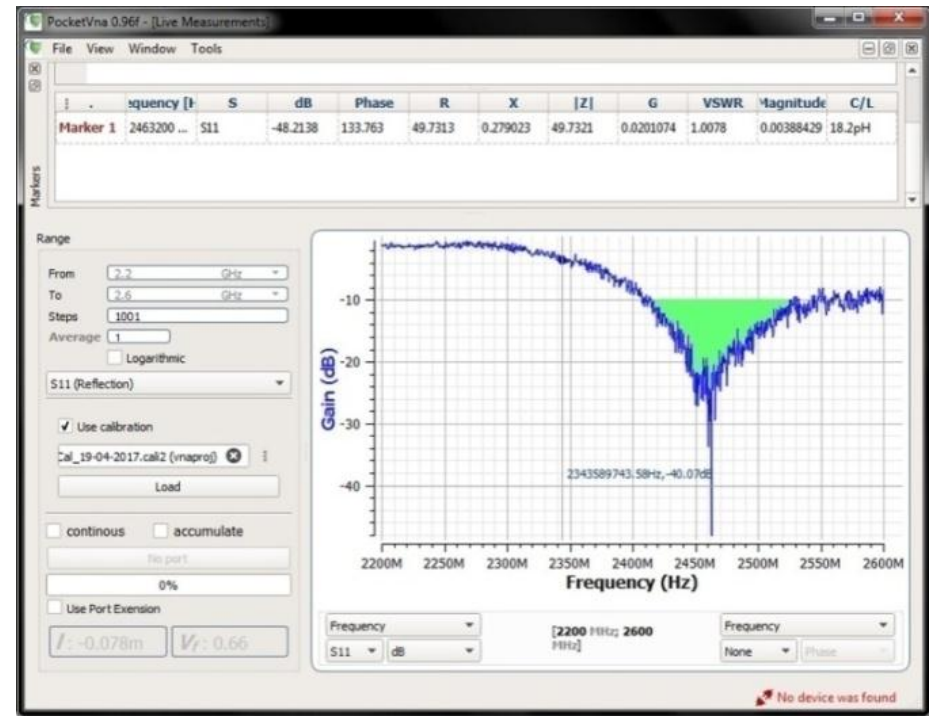

Fig. 15. Bandwidth for dual patch element.

From both figure above, it can be explained that the bandwidth for single element span from $2.372 \mathrm{GHz}$ to $2.456 \mathrm{GHz}$. In which the bandwidth reaches $84 \mathrm{MHz}$. In other hand for dual element has range from $2.414 \mathrm{GHz}$ until $2.525 \mathrm{GHz}$, so that the result is $111 \mathrm{MHz}$.

\subsection{Comparison}

The design of single and dual triangle patch microstrip antenna utilizing proximity coupled feeding technique is compared to the single and dual triangle antenna which is used the coaxial probe feeding technique. The result of the comparison is shown in Table 3. 
Table 3. Comparison between proximity and coaxial probe feeding.

\begin{tabular}{|c|c|c|c|c|}
\hline \multirow{2}{*}{ Parameters } & \multicolumn{2}{|c|}{ Single Element } & \multicolumn{2}{c|}{ Dual Element } \\
\cline { 2 - 5 } & Coaxial Probe & Proximity & Coaxial Probe & Proximity \\
\hline $\begin{array}{c}\text { Return } \\
\text { Loss (dB) }\end{array}$ & -15.93 & -51.913 & -19.31 & -48.2138 \\
\hline VSWR & 1.294 & 1.0059 & 1.24 & 1.0078 \\
\hline $\begin{array}{c}\text { Bandwidth } \\
(\mathrm{MHz})\end{array}$ & 42 & 84 & 28 & 111 \\
\hline $\begin{array}{c}\text { Resonance } \\
\text { Frequency } \\
(\mathrm{GHz})\end{array}$ & 2.537 & 2.417 & 2.537 & 2.463 \\
\hline
\end{tabular}

\subsection{Fabrication design}

The single and dual triangle patch microstrip antenna using proximity coupled feeding technique has been fabricated on a substrate material FR-4, which is shown in Figure 16 and Figure 17 respectively.

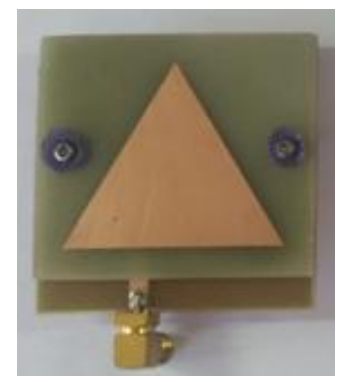

Fig. 16. Single triangle patch.

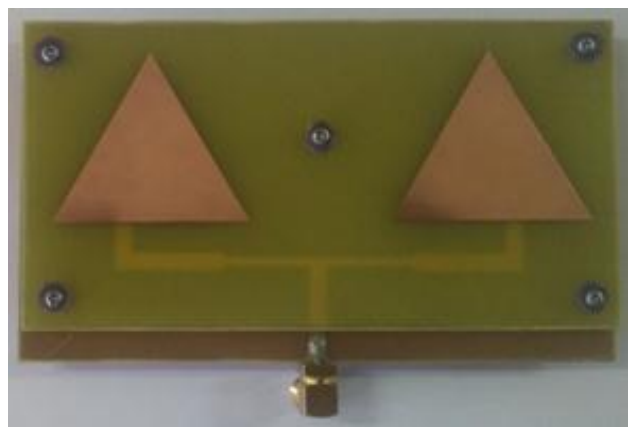

Fig. 17. Dual triangle patch.

\section{Conclusion}

Finally single and dual element triangle patch microstrip antenna is fabricated and presented. The both proposed antenna is suitable for WLAN $2.4 \mathrm{GHz}$ application. The both fabricated antenna has good performance and almost perfectly impedance matching. It can be concluded that the parameter result of proximity coupled feeding techniques has better performance compare to the coaxial feeding techniques. 
Author gratefully thank to National Institute of Technology (ITN) Malang, for their support in funding this research. We also would like to express our gratitude to the head of Telecommunication Laboratory, for their contribution during measurement.

\section{References}

1. D. Singh, K.A. Gupta, R.K. Prasad, Design and Analysis of C-Shaped Microstrip Patch Antenna for Wideband Application. In: Proceedings of the Conference on Advances in Communication and Control Systems-2013 (CAC2S). USA : Atlantis Press (2013). pp. 425-428. https://www.atlantis-press.com/proceedings/cac2s-13/6349

2. G. Kumar, K.P. Ray. Broadband microstrip antennas, USA: Artech House, Inc. (2005). pp. 3-4.

https://books.google.co.id/books/about/Broadband_Microstrip_Antennas.html?id=wfl8 4429CsEC\&redir esc $=\mathrm{y}$

3. C.A. Balanis. Antenna theory analysis and design. 3rd edition. USA: John Willey and Sons (2005). p. 811.

https://books.google.co.id/books? id=iFEBCgAAQBAJ\&printsec $=$ frontcover\&dq $=$ Ante nna+Theory+Analysis+and+Design\&hl $=$ en $\&$ sa $=X \& v e d=0 a h U K E w j 674 \mathrm{~m} 10 \quad 7 \mathrm{YAhV}$ CuY8KHRFsBqwQ6AEIKDAA\#v=onepage\&q=Antenna\%20Theory\%20Analysis\%2 0and\%20Design\&f=false.

4. K.P. Kumar, K.S. Rao, T. Sumanth, N.M. Rao, R.A. Kumar, Y. Harish. IJARCCE, 2 , 2:1276-1281 (2013). https://www.ijarcce.com/upload/february/29Effect $\% 20$ of $\% 20$ feeding\%20-tallurisumanth.pdf.

5. S. Sotyohadi, S.H. Pramono, M. Sarosa. Design and fabrication of "Ha" shape-slot microstrip antenna for WLAN $2.4 \mathrm{GHz}$. In: Proceedings of Second International Conference on Electrical Systems, Technology and Information 2015 (ICESTI 2015). F. Pasila, Y. Tanoto, R. Lim, M. Santoso, N. Pah (Eds). Singapore: Springer (2015). pp. 383-391. https://link.springer.com/chapter/10.1007/978-981-287-988-2_41\#citeas

6. H.K. Varshney, M. Kumar, A.K. Jaiswal, R. Saxena, K. Jaiswal. IJCET, 4,3(2014). http://inpressco.com/wp-content/uploads/2014/05/Paper391418-14231.pdf.

7. A. Gupta. Design and fabrication of dual and triple band microstrip patch antenna using proximity coupling for wireless application. [Thesis]. Thapar Universiti, Patiala, India (2012). p. 19. http://dspace.thapar.edu:8080/jspui/bitstream/10266/1858/3/1858.pdf

8. V.V.Khairnar, B.V.Kadam, K.R.Khandagle. Design of equilateral triangular microstrip patch antenna with co-axial feeding technique. International Conference on Recent Trends in engineering \& Technology - 2013(ICRTET'2013) (Kodaikanal, India, 2013). Special Issue of International Journal of Electronics, Communication \& Soft Computing Science \& Engineering:37-39 (2013).

http://www.ijecscse.org/papers/Special\%20Issue\%202013/Design\%20of\%20Equilatera 1\%20Triangular $\% 20 \mathrm{Microstrip} \% 20 \mathrm{Patch} \% 20$ Antenna $\% 20$ with $\% 20 \mathrm{Co}-$ axial $\% 20$ Feeding\%20Technique.pdf

9. R.K. Vishwakarma, J.A. Ansari, M.K. Meshram. Indian Journal of Radio Space Physics, 35:293-296 (2006).

http://www.scirp.org/(S(351jmbntvnsjtlaadkposzje))/reference/ReferencesPapers.aspx ?ReferenceID $=1846481$

10. Y.S.H. Khraisat, M.M. Olaimat, S.N. Abdel-Razeq. Applied Physics Research, 4, 2 : 75-81(2012).

http://www.ccsenet.org/journal/index.php/apr/article/viewFile/13750/11280.

11. P. Arunagiri, C.N. Kumar, K. Adhavan. IJRASET, 4, IV:88-92 (2016).

https://www.ijraset.com/fileserve.php?FID=4397. 
12. P.S. Nakar. Design of a compact microstrip patch antenna for use in wireless cellular devices. [Thesis]. Florida State University, Florida, USA (2004). p. 51

http://diginole.lib.fsu.edu/islandora/object/fsu:181039/datastream/PDF/view. page 51.

13. W.D. Pradipta, E. Setijdi, G. Hendrantoro. Jurnal Teknik ITS, 1, 1 (2012).

http://ejurnal.its.ac.id/index.php/teknik/article/view/64 